\title{
Changes in the Ovarian Polyamine Content and Seed Set Efficiency of Cotton by the Plant Growth Regulator BM86
}

\author{
Androniki C. Bibi, Derrick M. Oosterhuis, Evangelos D. Gonias \\ Department of Crop, Soil, and Environmental Sciences, University of Arkansas, Fayetteville, USA. \\ Email: an-bibi@hotmail.com
}

Received June $7^{\text {th }}, 2012$; revised July $6^{\text {th }}, 2012$; accepted July $19^{\text {th }}, 2012$

\begin{abstract}
Naturally occurring polyamines in plants have been implicated in floral initiation, and fruit development. The plant growth regulator BM86 was formulated to stimulate seed production and fruit growth by enhancing polyamine synthesis. The objectives of this study were to determine the effect of BM86 on free polyamine content in cotton (Gossypium hirsutum L.) ovaries and on seed set efficiency, and also to investigate genotypic differences in ovarian polyamine content. BM86 was applied at the first flower stage and two weeks later at $2.34 \mathrm{~mL} / \mathrm{ha}$. This study showed that application of BM86 had a significant positive effect on ovarian polyamine content of cotton. Putrescine and spermidine one week after the $1^{\text {st }}$ BM86 application and putrescine two week after the $1^{\text {st }}$ BM86 application, were significantly increased compared to the untreated control. Higher seed set efficiency with the BM86 application was observed when the total number of seeds was used for the calculation. However, when the number of harvestable seeds was used to calculate seed set efficiency BM86 had no significant effect. In addition, application of BM86 did not significantly alter seedcotton yield of the crop. Only small differences in ovarian polyamine content were detected among the genotypes tested, possibly due to the narrow genetic pool of the commercial cotton genotypes used. Application of BM86 can significantly increase cotton seed number by enhancing polyamines biosynthesis, but further research is needed to determine how to capitalize on the increased potential number of harvestable seeds.
\end{abstract}

Keywords: Putrescine; Spermidine; Spermine; BM86; Gossypium hirusutm L.; Ovaries

\section{Introduction}

Cotton (Gossypium hirsutum L.) is a major industrial crop grown for fiber, fuel, and feed, but yield suffers from various biotic and abiotic stresses during the reproductive development. The number of seed per boll is an important basic component of both cotton yield and fiber quality. Seed number is a function of the number of locules (carpels) per boll and the number of ovules per locule [1] (Stewart 1986). Several factors such as the lack of seed fertilization, post-fertilization termination of embryo growth, cultivar and environment can contributed to the variation in the number of seed per boll [2] (Turner et al. 1977).

Polyamines are organic polycations involved in DNA replication and cell division [3] (Bais and Ravishankar 2002), and they are intimately involved in successful reproductive development of the crop, cell multiplication and cell differentiation during organogenesis [4] (Costa et al. 1984). Polyamines can act as regulators of many physiological processes including flower induction [5-9] (Evans and Malmberg 1989; Faust and Wang 1992; Bagni et al. 1993; Bouchereau et al. 1999; Kakkar and
Sawhney 2002). According to Costa et al. (1984) [10] polyamines play an important role in flowering, pollination and early fruit development. Kloareg et al. (1986) [11] indicated that polyamines are indispensable to plants at the time of flowering and early fruit development.

The documented importance of polyamines in reproductive development directed many researchers to exogenously applying polyamines in an effort to enhance fruit development. Reports in mango (Mangifera indica L.) [12] (Singh and Janes 2000) and apricot (Prunus armeniaca L.) [13] (Alburquerque et al. 2006) showed improved fruit retention and yield. However, exogenous application of polyamines in row crops is not a practical management practice due to the high cost of the material. An affordable alternative is to apply synthetic plant growth regulators.

The plant growth regulator BM86 (active ingredient GA14; Goëmar Laboratories, Saint-Malo, France) is an elicitor that contains oligosaccharides reported to re- gulate the synthesis of endogenic polyamines. Broquedis et al. (1995) [14] investigated the effect of GA14 on the composition of polyamines in grapes (Vitis vinifera L.), 
and showed an increase in the accumulation of polyamines particularly at the end of the first stage of fruit development. Treatment with GA14 increased the numbers, weight and growth of the fruit, and this was related to a significant increase in polyamine content in the flowers and in the fruit. It appears, therefore, that the BM86 contains elicitors which stimulate the metabolism of polyamines of endogenous growth.

Numerous anecdotal reports with horticulture plants have shown that BM86 acts to stimulate reproductive development of the plant. According to these reports (Anonymous 2008) [15] BM86 increased yield and oil production of olives (Olea europeae L.), promoted uniform fertilization and fruit set in grapes (Vitis vinifera L.) and resulted in increased fruit size and total yield in citrus (Citrus sp. L). In cotton there is a single report that associates BM86 application with increased yield [16] (Rethwisch 2006). However, there are no reports that examine the effect of BM86 on polyamines in cotton. Therefore in this study it was hypothesized that polyamine concentration in cotton ovaries will increase with the application of BM86 and this will result in increased seed set efficiency of cotton. Also, it was hypothesized that genotypic differences in cotton will exist. The objectives were to determine the effect of the BM86 on free polyamines in cotton ovaries, and seed set efficiency of cotton, and to investigate genotypic differences in ovule polyamine content

\section{Material and Methods}

\subsection{Plant Establishment}

A field study was conducted at the Lon Mann Cotton Research Station in Marianna Arkansas $\left(34^{\circ} 5^{\prime} \mathrm{N}, 90^{\circ} 5^{\prime} \mathrm{W}\right)$ in 2005 and 2006. The cultivars used were DP444BR, ST5599BR, and FM960BR. The soil was a Captina silt loam (typical fragiudult). The experimental plot size was four rows by $15 \mathrm{~m}$ and the plant population 10 plants per $\mathrm{m}^{2}$. The study was furrow-irrigated based on an irrigation scheduler program [17] (University of Arkansas Cooperative Extension Database Service 2007). The fertilization program was determined by preseason soil tests and recommended values for cotton. Weed and insect control were conducted according to Arkansas extension recommendations. At first flower BM86 (Goëmar Laboratories, Saint-Malo, France) was applied to the right 2 rows of each plot at $2.34 \mathrm{~mL} / \mathrm{ha}$ (recommended rate from Goëmar Laboratories) with a backpack $\mathrm{CO}_{2}$ sprayer calibrated to deliver $94 \mathrm{~L} / \mathrm{ha}$ of spraying solution. The left two rows were used as the control. The day before the $1^{\text {st }}$ application of BM86, the flowering node was determined and 10 first-sympodial fruiting position white flowers were collected from each plot. Sampling was performed weekly using first-position flowers two nodes higher than the previous position, for a total of three weeks. BM86 was reapplied two weeks after the first application.

\subsection{Number of Ovules/Ovary}

Half of the flowers that were collected were used to determine the number of ovules per ovary. The procedure involved separating the ovary from the petals and sepals and dissecting the ovaries to determine the number of ovules in each ovary.

\subsection{Polyamines Analysis}

Chemical: Putrsecine dihydrochloride, spermidine trihydrochloride, spermine tetrahydrochloride, hexamethylanediamine, dansyl chloride, $99.9 \%$ acetone, and sodium carbonate were purchased from Sigma Aldrich.

Extraction of Tissues: Polyamines were extracted based on Smith and Davies [18] (1985) with modifications needed for cotton. Cotton ovaries were separated from petals and sepals. Ovary tissue $(0.1 \mathrm{~g})$ was homogenized in mortars with pestles in $0.2 \mathrm{~N} \mathrm{HClO}_{4}$. For unfortified samples, $100 \mu \mathrm{L} 1 \mathrm{mM}$ hexamethylanediamine in $0.2 \mathrm{~N} \mathrm{HClO}_{4}$ was added to the tissue prior to the homogenization as an internal standard. The final volume of $2 \mathrm{~mL}$ was obtained by adding $1900 \mu \mathrm{L} 0.2 \mathrm{~N} \mathrm{HClO}_{4}$. For the fortified samples, $100 \mu \mathrm{L} 1 \mathrm{mM}$ hexanediamine in $0.2 \mathrm{~N} \mathrm{HCLO}_{4}$ was added plus the desired volume of fortification solution in $0.2 \mathrm{~N} \mathrm{HClO}_{4}$, which was $120 \mu \mathrm{L}$ $1 \mathrm{mM}$ of Putrescine in $0.2 \mathrm{~N} \mathrm{HClO}_{4}, 120 \mu \mathrm{L} 1 \mathrm{mM}$ Spermidine in $0.2 \mathrm{~N} \mathrm{HClO}_{4}$, and $120 \mu \mathrm{L} 1 \mathrm{mM}$ of Spermine in $0.2 \mathrm{~N} \mathrm{HClO}_{4}$. The final volume of $2 \mathrm{~mL}$ was obtained by adding $1540 \mu \mathrm{L} 0.2 \mathrm{~N} \mathrm{HClO}_{4}$. An aliquot of $1.5 \mathrm{~mL}$ of the homogenate was transferred to $2 \mathrm{~mL}$ plastic micro centrifuge tubes and the samples were centrifuged at $4{ }^{\circ} \mathrm{C}$ for 20 minutes at $13,000 \mathrm{rpm}$.

Dansylation: The polyamines were derivatized by adding $50 \mu \mathrm{L}$ aliquots of the supernatant to $500 \mu \mathrm{L} 21.2$ $\mathrm{mM}$ aqueous $\mathrm{Na}_{2} \mathrm{CO}_{3}, 200 \mu \mathrm{L} 99.9 \%$ acetone, and $50 \mu \mathrm{L}$ of $12.5 \mathrm{mM}$ dansyl chloride in acetone. The mixture was incubated in a thermal reaction block at $60^{\circ} \mathrm{C}$ for $1 \mathrm{~h}$ in the dark. After $1 \mathrm{~h}$ in the thermal block the samples were removed and cooled to near room temperature, and $50 \mu \mathrm{L}$ of $1 \mathrm{~N} \mathrm{HClO}_{4}$ was added to the mixture and mixed. The samples were then centrifuged at $4^{\circ} \mathrm{C}$ for 20 minutes at $13,000 \mathrm{rpm}$ after which $700 \mu \mathrm{L}$ of centrifugate was transferred into $2 \mathrm{~mL}$ sample vial and $700 \mu \mathrm{L}$ of $0.02 \mathrm{~N}$ $\mathrm{HClO}_{4}$ was added The samples were capped and mixed before injection into the High Performance Liquid Chromatography (HPLC). Derivatization needs to be in a basic solution, whereas the final solution for HPLC needs to be acidic.

Standard Preparation: A total of six standards were used for the preparation of the standard curves. The standards included putrescine, spermidine, spermine and the 
internal standard hexamethylanediamine. The concentration of putrsecine and spermidine in the six standards ranged from 30 to $1 \mathrm{nmole} / \mathrm{mL}$, while the concentration of spermine ranged from 60 to $2 \mathrm{nmole} / \mathrm{mL}$. A $500 \mu \mathrm{L}$ aliquot of $1 \mathrm{mM}$ hexamethylanediamine was added to the first five standards, while an amount of $1.25 \mathrm{~mL}$ of $1 \mathrm{mM}$ hexamethylanediamine was added to the last one. The final volume was $10 \mathrm{~mL}$ for the first five standards and $25 \mathrm{~mL}$ for the final standard. To bring the standards to the final volume $0.2 \mathrm{~N} \mathrm{HClO}_{4}$ was used.

HPLC Analysis: HPLC analysis was performed in a Hitachi HPLC (Hitachi High Technologies America, Inc., Canada) system that included a model L-7100 pump, an L-7200 autosampler, a D-7000 interface, and an ERC3415a degasser, and an L-7480 fluorescence detector. The column used in this analysis was a $25 \mathrm{~cm} \times 2 \mathrm{~mm}$ id 0.5 micron Phenomenex Gemini C18. Injection volume was $40 \mu \mathrm{L}$. Polyamines were eluted from the column at $0.3 \mathrm{~mL} / \mathrm{min}$ with a methanol:water $(\mathrm{v} / \mathrm{v})$ gradient from $70 \%$ methanol to $95 \%$ methanol over $6 \mathrm{~min}$ and then remaining at $95 \%$ methanol for $16.4 \mathrm{~min}$. The system was re-equilibrated with $70 \%$ methanol for $15 \mathrm{~min}$ before the next injection. For dansyl polyamines, an excitation wavelength of $365 \mathrm{~nm}$ was used with an emission wavelength of $510 \mathrm{~nm}$. Data collection and processing was with Hitachi System Manager (HSM) software on the internal standard concentration.

\subsection{Seed Set Efficiency (SSE) and Seedcotton Yield}

At harvest five bolls were hand-picked from each plot from the same node from which flowers had been previously collected, for both control and BM86 treated plants. The final number of seed per boll was determined from the hand-picked bolls, and seed set efficiency was calculated using the equation: [seed set efficiency $=(\#$ of seeds/\# of ovules) $\times 100$ ]. In a cotton boll at harvest there are undeveloped ovules and harvestable seeds. For our experiments seed set efficiency was calculated using both the total seed number (undeveloped ovules + harvestable seeds) and the number of the harvestable seeds. Seedcotton yields were determined by mechanically harvesting each individual sub-plot.

\subsection{Statistical Analysis}

The experimental design was a randomized complete block (RCBD) with five replications. The treatment design was split-plot in strips (split-block) with main factor being "cultivars" that were randomly assigned to the experimental plots, and sub-factor being "BM86 application" that was not randomly assigned to allow easier harvest. The year effect was considered random and not included in the model. Data from each year was analyzed and presented separately. Statistical analysis was performed with the JMP 6 Software (SAS Institute Inc., Cary, NC). Interactions and main effects were tested with Analysis of Variance (ANOVA) at $\alpha \leq 0.05$, when significant effects were detected means were separated with Student's t-test $(\alpha \leq 0.05)$.

\section{Results}

The analysis of the data showed no significant "cultivar $\times$ BM86 $\times$ year" interaction therefore "cultivar $\times$ BM86 application" was analyzed separately for each years of the study for each parameter measured. In addition there was no significant "cultivar $\times$ BM86 application" interaction in either year (Table 1). The lack of interaction allowed us to analyze the main effects of "nodal position" and "BM86 application" on putrescine spermidine, spermine, seed set efficiency (calculated with the total seed number), seed set efficiency (calculated with the harvestable seed number), and seedcotton yield.

\subsection{Effect of BM86 Application on Ovarian Polyamine Content}

One week after the $1^{\text {st }}$ BM86 application: Ovarian putrescine concentration was significantly increased compared to the untreated control plant in $2005(\mathrm{P}=0.0047$; Figure 1(A)). However, application of BM86 did not significantly affect spermidine and spermine concentration with $\mathrm{P}=0.3927$ and $\mathrm{P}=0.9337$, respectively (Figure 1(I)). These data were further supported in 2006 where again one week after the BM86 application the putrescine content was significantly higher compared to the control $(\mathrm{P}=0.0390$; Figure 1(II)). In addition in 2006 the BM86 application significantly increased the spermidine content of cotton ovaries $(P=0.0094)$, but again the effect on spermine was not significant $(\mathrm{P}=0.3791)$ (Figure 1(B)).

Two weeks after the $1^{\text {st }}$ BM86 application: The putrescine content of cotton ovaries continued to be signifi-

Table 1. The statistical significant for the "cultivar $\times$ BM86 application" interaction of all the parameters measured in 2005 and 2006.

\begin{tabular}{lcc}
\hline \multirow{2}{*}{ Variables measured } & "Cultivar $\times$ BM86 application” \\
\cline { 2 - 3 } & 2005 & 2006 \\
\hline Putrescine & 0.17 & 0.57 \\
Spermidine & 0.99 & 0.46 \\
Spermine & 0.19 & 0.24 \\
$\begin{array}{l}\text { Seed set efficiency (total seed } \\
\text { number) }\end{array}$ & 0.54 & 0.26 \\
$\begin{array}{l}\text { Seed set efficiency (harvestable } \\
\text { seed number) }\end{array}$ & 0.99 & 0.59 \\
Seedcotton yield & 0.64 & 0.46 \\
\hline
\end{tabular}




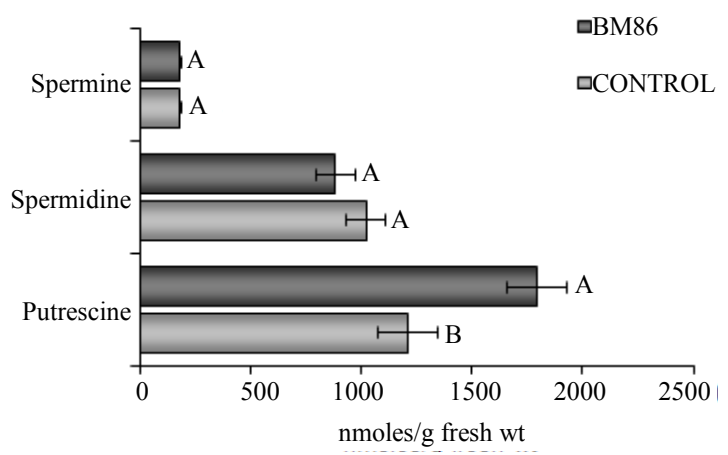

(I)

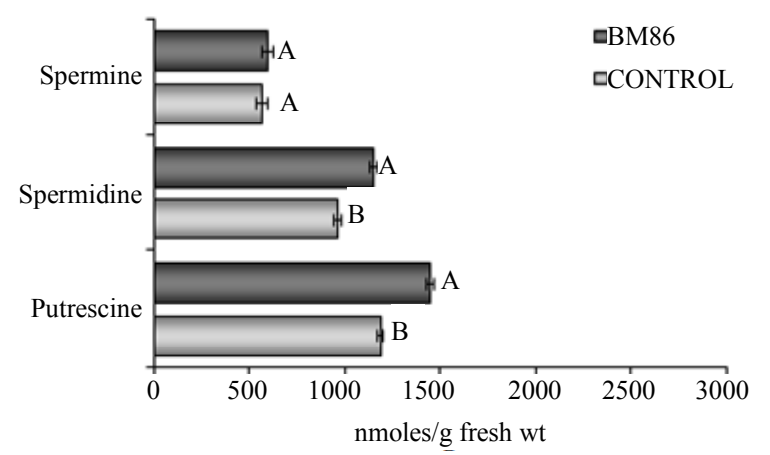

(II)

Figure 1. The effect of the plant growth regulator BM86 polyamine concentration of cotton ovaries one week after the first BM86 application in 2005 (I) and 2006 (II). Pair of columns for each polyamine with the same letter are not significantly different for $\alpha=0.05$ ( \pm 1 std error bars are shown).

cantly increased compared to the untreated control plant $(\mathrm{P}=0.0492$; Figure 2(I)). However the BM86 application did not significantly affect either spermidine or spermine concentration $(\mathrm{P}=0.0643$ and $\mathrm{P}=0.2852$, respectively) (Figure 2(I)). Similar effects of BM86 were recorded in 2006 with the putrescine content significantly higher compared to the control $(\mathrm{P}=0.0192$; Figure 2(II)), and spermidine and spermine concentration not significantly affected $(\mathrm{P}=0.0611$ and $\mathrm{P}=0.2539$, respectively) (Figure 2(II)).

One week after the 2nd BM86 application: The BM86 application did not significantly affect any of the three polyamines quantified in 2005 (Figure 3(I)). The P-values for putrescine, spermidine, and spermine were $\mathrm{P}=0.5529$, $\mathrm{P}=0.0717$, and $\mathrm{P}=0.2273$, respectively. In 2006, one week after the BM86 application the ovarian putrescine content was not significantly altered $(\mathrm{P}=0.1780$; Figure 3(II)), whereas the spermidine concentration of cotton ovaries significantly increased compared to the untreated control $(\mathrm{P}=0.0124)$. Spermine was not detected in cotton ovaries one week after the $2^{\text {nd }}$ BM86 application.

\subsection{Effect of BM86 Application on Seed Set Efficiency and Seedcotton Yield}

In 2005 BM86 application significantly increased the seed set efficiency of cotton when calculated using the total number of seeds ( $P=0.0423$; Figure 4(I)), however application of BM86 did not significantly affect seed set efficiency when it was calculated with just the number of harvestable seeds $(P=0.3287)$. Similar data were observed in 2006, the seed set efficiency calculated by the total seed number was significantly increased after BM86 application ( $\mathrm{P}=0.0046$; Figure 4(II)), while when calculated with just the number of harvestable seeds the effect was not significant $(P=0.7434)$. The non-significant effect of BM86 application on seed set efficiency (i.e. of harvestable seeds) was reflected in the non-significant effect on seedcotton yield in either year of the study (Figure 5).

\subsection{Effect of Cultivars on Ovarian Polyamine Content}

One week after the $1^{\text {st }}$ BM86 application: In 2005 the cultivar effect was not significant for putrescine $(\mathrm{P}=$ $0.5119)$, spermidine $(\mathrm{P}=0.1812)$, or spermine $(\mathrm{P}=$ 0.3451 ) (Table 2). In 2006 there were no cultivar differences for putrescine and spermine $(\mathrm{P}=0.1926$ and $\mathrm{P}=$ 0.2767 , respectively), but there were differences for spermidine ( $\mathrm{P}=0.0439)$ (Table 2). Among the genotypes tested, FM960BR showed significantly higher ovarian spermidine content compared to DP444BR and ST5599BR.

Two weeks after the $1^{\text {st }}$ BM86 application: In 2005, the putrescine, spermidine and spermine concentrations of cotton ovaries did not differ significantly among the cultivar (Table 3). In 2006 there were cultivar differences for putrescine and spermine $(\mathrm{P}=0.0087$ and $\mathrm{P}=0.0369$ respectively), but the spermidine concetration was not significantly changed $(\mathrm{P}=0.1499)$ (Table 3 ). Among the genotypes tested FM960BR showed significantly higher ovarian putrescine content compared to DP444BR and ST5599BR, and DP444BR showed significantly higher spermine concentration compared to ST55899BR.

One week after the $2^{\text {nd }}$ BM86 application: In 2005, there were no cultivar differences for spermidine and spermine concentration of cotton ovaries (Table 4). However the cultivar effect was significant for putrescine concentration $(\mathrm{P}=0.0349)$. Among the genotypes tested FM-960BR and ST5599BR showed significantly higher putrescine compared to DP444BR. In 2006 neither putrescine nor spermidine concentration of cotton ovaries were significantly affected by the cultivar effect with $\mathrm{P}=$ 0.1780 and $\mathrm{P}=0.9024$, respectively (Table 4).

\subsection{Effect of Cultivars on Seed Set Efficiency and Seedcotton Yield}

There were no cultivar differences in 2005 and 2006 for seed set efficiency calculated by the total seed number 


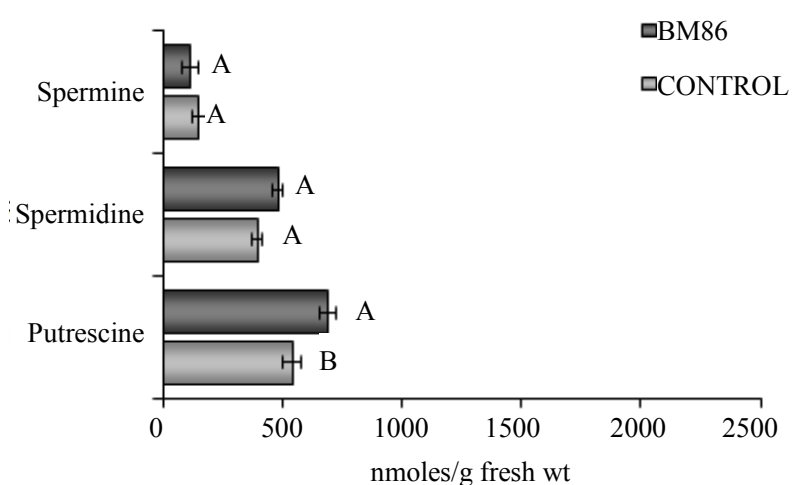

(I)

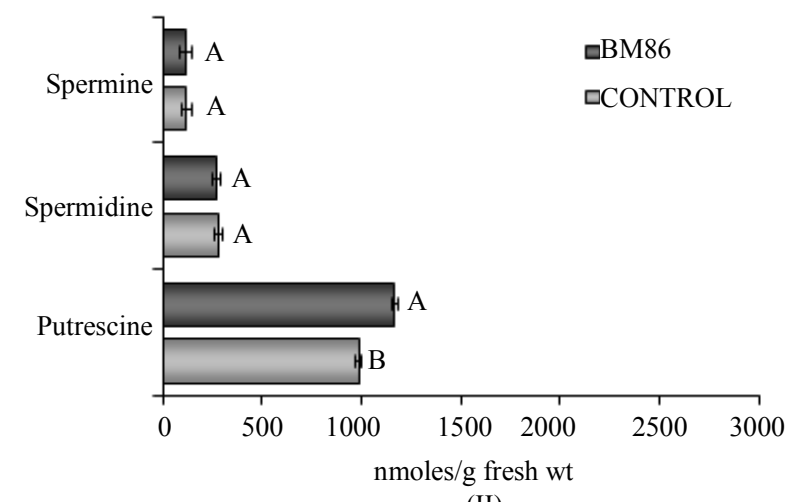

(II)

Figure 2. The effect of the plant growth regulator BM86 on the polyamine concentration of cotton ovaries two weeks after the first BM86 application in 2005 (I) and 2006 (II). Pair of columns for each polyamine with the same letter are not significantly different for $\alpha=0.05$ ( \pm 1 std error bars are shown).

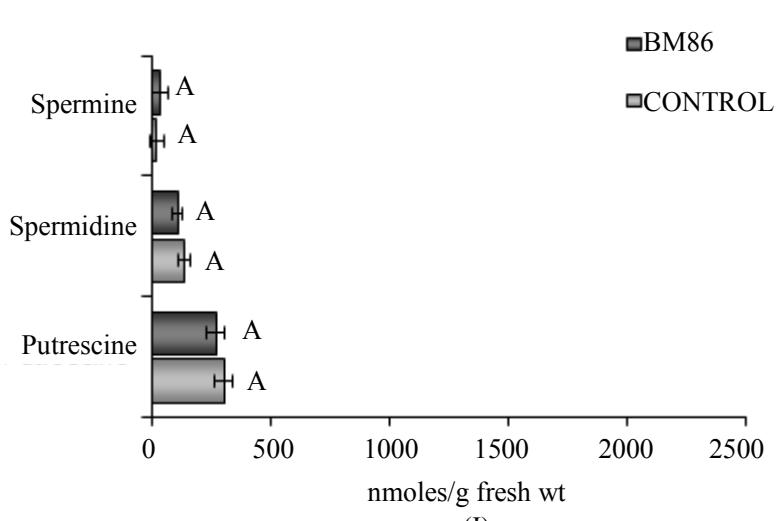

(I)

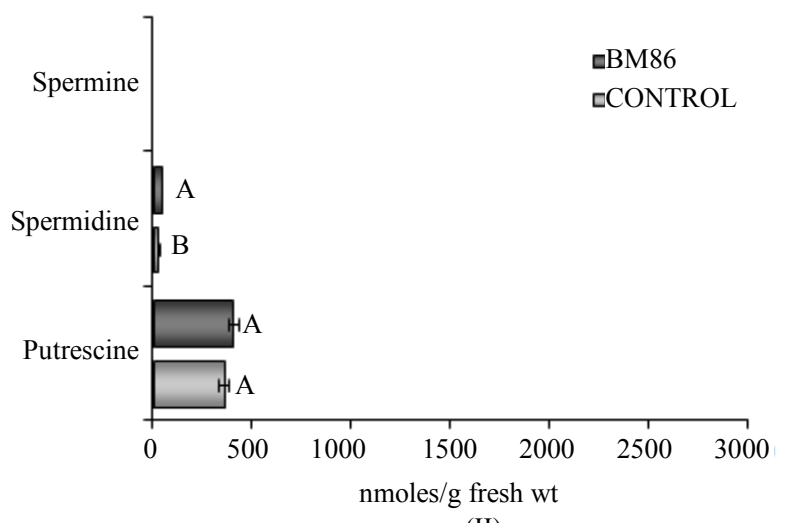

(II)

Figure 3. The effect of the plant growth regulator BM86 polyamine concentration of cotton ovaries one week after the second BM86 application in 2005 (I) and 2006 (II). Pair of columns for each polyamine with the same letter are not significantly different for $\alpha=0.05$ ( \pm 1 std error bars are shown).

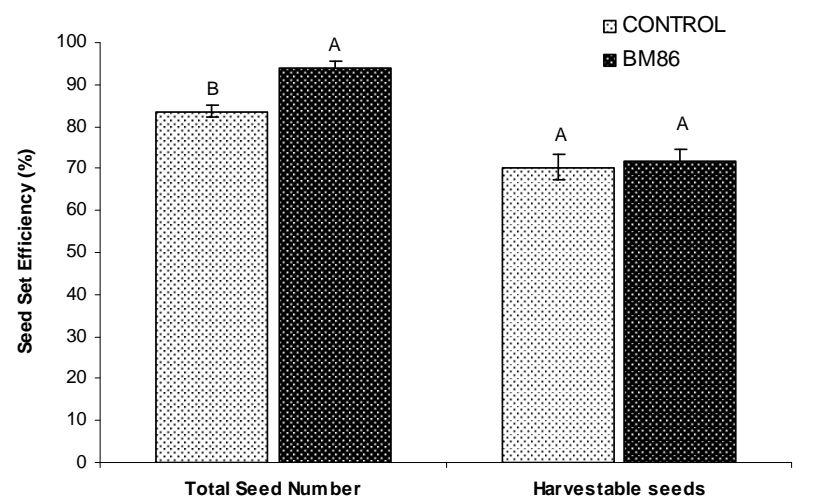

(I)

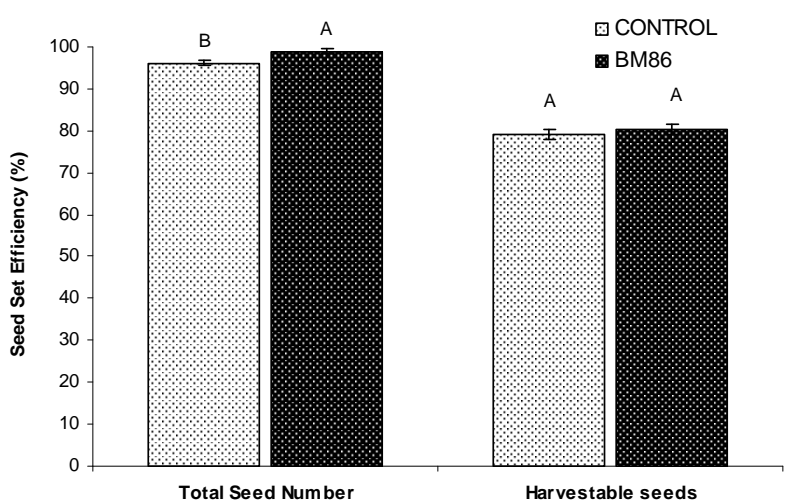

(II)

Figure 4. The effect of BM86 on seed set efficiency of cotton in 2005 (I) and 2006 (II). Pairs of columns with the same letter are not significantly different for $\alpha=0.05$ ( \pm 1 std error bars are shown).

and in seed set efficiency calculated by the harvestable seed number (Table 5). In addition, the cultivar effect was not significant for seedcotton yield in either year of the study with $\mathrm{P}=0.2209$ (2005) and $\mathrm{P}=0.6572$ (2006) (Table 6).

\section{Discussion}

This study showed that application of BM86 had a significant positive effect on ovarian polyamine content of cotton. The results were positive for putrescine and spermidine one week after the $1^{\text {st }}$ BM86 application and 


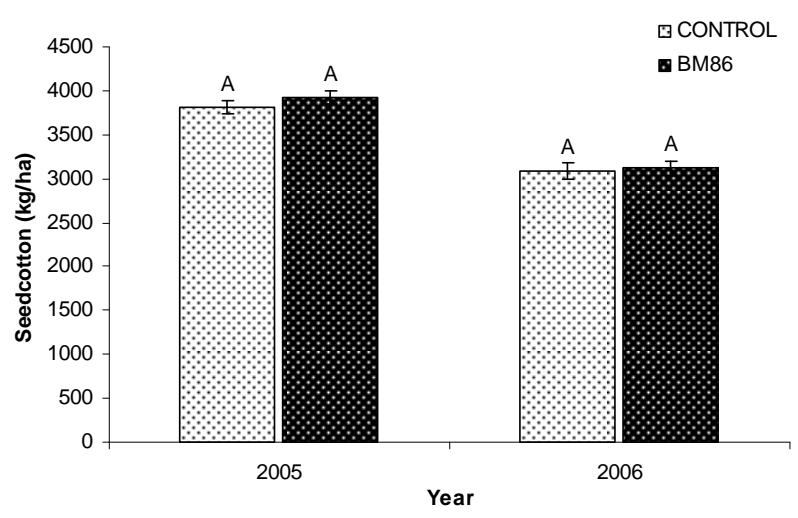

Figure 5. The effect of BM86 on seedcotton yield in 2005 and 2006. Pair of columns within a year with the same letter are not significantly different for $\alpha=0.05$ ( \pm 1 std error bars are shown). and for putrescine two weeks after the $1^{\text {st }}$ BM86 application. Broquedis et al. (1995) [14] investigated the effect of GA14, the active ingredient in BM86, and showed an increase in the accumulation of polyamines in grapes (Vitis vinifera L.). In addition, there are several anecdotal reports in horticulture crops that associate the BM86 application with increased polyamine levels; however this is the first documented report of increased polyamines in cotton ovaries. Among the genotypes tested only FM960BR showed increased polyamine content, however this was not consistent from year to year. Polyamines have been quantified in diverse rice cultivars [19] (Lepri et al. 2002), while post-harvest changes in polyamines have been measured in two diverse rose species [20] (Sood and Nagar 2008). This is the first report of cotton cultivar screening for polyamines in ovarian tissue after

Table 2. Cultivar effect on ovarian polyamine content one week after the $1^{\text {st }}$ application of BM86 in 2005 and 2006.

\begin{tabular}{|c|c|c|c|c|c|c|c|c|c|c|c|c|}
\hline \multirow{3}{*}{ Cultivars } & \multicolumn{4}{|c|}{ Putrescine } & \multicolumn{4}{|c|}{ Spermidine } & \multicolumn{4}{|c|}{ Spermine } \\
\hline & \multicolumn{2}{|c|}{2005} & \multicolumn{2}{|l|}{2006} & \multicolumn{2}{|l|}{2005} & \multicolumn{2}{|l|}{2006} & \multicolumn{2}{|c|}{2005} & \multicolumn{2}{|l|}{2006} \\
\hline & \multicolumn{12}{|c|}{ nmoles/g fresh wt } \\
\hline DP444BR & 1300.3 & $a^{1}$ & 1403.5 & $\mathrm{a}$ & 862.1 & $\mathrm{a}$ & 853.1 & $\mathrm{~b}$ & 187.1 & $\mathrm{a}$ & 517.3 & a \\
\hline FM960BR & 1750.8 & $\mathrm{a}$ & 1461.9 & $\mathrm{a}$ & 1105.3 & $\mathrm{a}$ & 1320.6 & $\mathrm{a}$ & 196.7 & $\mathrm{a}$ & 682.9 & a \\
\hline ST5599BR & 1442.2 & $\mathrm{a}$ & 1074.5 & $\mathrm{a}$ & 883.6 & $\mathrm{a}$ & 979.9 & $\mathrm{~b}$ & 157.1 & $\mathrm{a}$ & 528.6 & a \\
\hline P-Value & 0.511 & & 0.1926 & & 0.1812 & & 0.043 & & 0.34 & & 0.2767 & \\
\hline
\end{tabular}

${ }^{1}$ Cultivars with the same letter in a column are not significantly different for $\alpha=0.05$.

Table 3. Cultivar effect on ovarian polyamine content two weeks after the $1^{\text {st }}$ application of BM86 in 2005 and 2006.

\begin{tabular}{|c|c|c|c|c|c|c|c|c|c|c|c|c|}
\hline \multirow{3}{*}{ Cultivars } & \multicolumn{4}{|c|}{ Putrescine } & \multicolumn{4}{|c|}{ Spermidine } & \multicolumn{4}{|c|}{ Spermine } \\
\hline & \multicolumn{2}{|c|}{2005} & \multicolumn{2}{|l|}{2006} & \multicolumn{2}{|l|}{2005} & \multicolumn{2}{|c|}{2006} & \multicolumn{2}{|l|}{2005} & \multicolumn{2}{|c|}{2006} \\
\hline & \multicolumn{12}{|c|}{---------nmoles/g fresh wt--------- } \\
\hline DP444BR & 590.1 & $a^{1}$ & 904.8 & $\mathrm{~b}$ & 431.9 & $\mathrm{a}$ & 273.2 & $\mathrm{a}$ & 128.3 & $\mathrm{a}$ & 125.5 & $\mathrm{a}$ \\
\hline FM960BR & 609.4 & $\mathrm{a}$ & 1337.6 & $\mathrm{a}$ & 472.7 & $\mathrm{a}$ & 290.7 & $\mathrm{a}$ & 144.4 & $\mathrm{a}$ & 111.7 & $\mathrm{ab}$ \\
\hline ST5599BR & 640.9 & $\mathrm{a}$ & 975.6 & $\mathrm{~b}$ & 405.5 & $\mathrm{a}$ & 253.8 & $\mathrm{a}$ & 120.7 & $\mathrm{a}$ & 103.6 & $\mathrm{a}$ \\
\hline P-Value & 0.74 & & 0.0087 & & 0.3135 & & 0.1 & & 0.9632 & & 0.0 & \\
\hline
\end{tabular}

${ }^{1}$ Cultivars with the same letter in a column are not significantly different for $\alpha=0.05$.

Table 4. Cultivar effect on ovarian polyamine content one week after the $2^{\text {nd }}$ application of BM86 in 2005 and 2006.

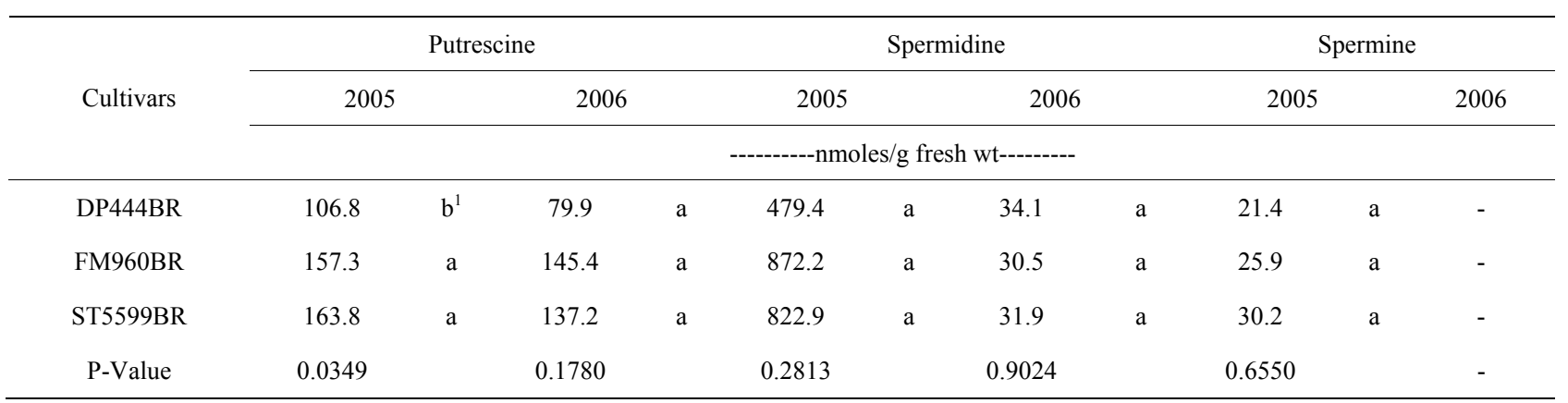

${ }^{1}$ Cultivars with the same letter in a column are not significantly different for $\alpha=0.05$. 
Table 5. The effect of cultivars on seed set efficiency of cotton calculated by the total seed number and by the number of the harvestable seeds in 2005 and 2006.

\begin{tabular}{|c|c|c|c|c|c|}
\hline \multirow{3}{*}{ Seed Record } & \multirow[t]{3}{*}{ Cultivars } & \multicolumn{4}{|c|}{ Seed Set Efficiency } \\
\hline & & \multicolumn{2}{|c|}{2005} & \multicolumn{2}{|c|}{2006} \\
\hline & & \multicolumn{4}{|c|}{$\%$} \\
\hline \multirow[t]{4}{*}{ Total seed number } & DP444BR & 70.3 & $a^{1}$ & 80.9 & $\mathrm{a}$ \\
\hline & FM960BR & 66.4 & $\mathrm{a}$ & 77.7 & $\mathrm{a}$ \\
\hline & ST5599BR & 76.3 & $\mathrm{a}$ & 80.7 & $\mathrm{a}$ \\
\hline & P-Value & 0.0584 & & 0.4405 & \\
\hline \multirow[t]{4}{*}{ Harvestable seeds } & DP444BR & 88.0 & $\mathrm{a}$ & 97.5 & $\mathrm{a}$ \\
\hline & FM960BR & 87.4 & $\mathrm{a}$ & 98.8 & $\mathrm{a}$ \\
\hline & ST5599BR & 91.3 & $\mathrm{a}$ & 96.3 & $\mathrm{a}$ \\
\hline & P-Value & 0.3008 & & 0.4386 & \\
\hline
\end{tabular}

${ }^{1}$ Cultivars in a column for each parameter with the same letter are not significantly different for $\alpha=0.05$.

Table 6. The effect of cultivars on seedcotton yield of cotton for 2005 and 2006.

\begin{tabular}{cccccc}
\hline Cultivars & \multicolumn{5}{c}{ Seedcotton } \\
\cline { 2 - 5 } & \multicolumn{5}{c}{2005} \\
\multicolumn{5}{c}{$\mathrm{kg} / \mathrm{ha}$} \\
\hline DP444BR & 3839.8 & $\mathrm{a}^{1}$ & 3158.3 & $\mathrm{a}$ \\
FM960BR & 3692.6 & $\mathrm{a}$ & 3155.6 & $\mathrm{a}$ \\
ST5599BR & 4056.2 & $\mathrm{a}$ & 2989.9 & $\mathrm{a}$ \\
P-Value & 0.2209 & & 0.6572 & \\
\hline
\end{tabular}

${ }^{1}$ Cultivars in a column with the same letter are not significantly different for $\alpha=0.05$.

BM86 application.

Polyamines have been associated with fruit set and the initial phase of fruit development in many horticulture plants, such as apple (Malus domestica L.) [10,21] (Costa and Bagni 1983; Biasi et al. 1991), pear (Pyrus communis L.) [22,23] (Crisosto et al. 1986; Crisosto et al. 1988), pepper (Capsicum annuum L.) [24] (Serrano et al. 1995), olive (Olea europeae L.) [25] (Rugini and Mencuccini 1985), mango (Mangifera indica L.) [26] (Singh and Singh 1995), and tomato (Solanum lycopersicum L.) [27] (Antognoni et al. 2002). This can be attributed to a possible involvement of polyamines in cell growth [3] (Bais and Ravishankar 2002). Therefore the increased levels of polyamines reported in our study were expected to result in improved seed set. Higher seed set efficiency with the BM86 application was observed when the total number of seeds was used for the calculation. However, when the number of harvestable seeds was used to calculate seed set efficiency BM86 did not have a significant effect. In addition, BM86 application did not significantly alter seedcotton yield of the crop. These data suggest that BM86 application may set the potential for higher seed set efficiency, but the cotton crop in Arkansas does not have the resources to develop the set seeds to harvestable seeds. In other locations such as California, higher cotton yields after application of BM86 [16] (Rethwich 2006) are possibly due to the higher productive environment [28] (Gonias et al. 2008). The lack of significant differences among the genotypes tested can be attributed to the narrow genetic pool of the current commercial genotypes.

\section{Acknowledgements}

The authors would like to acknowledge Dr. John Mattice for the significant help with the HPLC analysis.

\section{REFERENCES}

[1] J. McD. Stewart, "Integrated Events in Flower and Fruit," In: J. R. Mauney and J. M. Stewart, Eds., Cotton physiology, The Cotton Foundation, Memphis, 1986, pp. 261300 .

[2] J. H. Turner, J. M. Stewart, P. E. Hoskinson and H. H. Ramey, "Seed Setting Efficiency in Eight Cultivars of Upland Cotton," Crop Science, Vol. 17, No. 5, 1977, pp. 769-772.

doi:10.2135/cropsci1977.0011183X001700050023x

[3] H. P. Bais and G. A. Ravishankar, "Role of Polyamines in the Ontogeny of Plants and Their Biotechnological Applications," Plant Cell, Tissue and Organ Culture, Vol. 69, No. 1, 2002, pp. 1-34. doi:10.1023/A:1015064227278

[4] G. Costa, R. Baraldi and N. Bagni, "Influence of Putrescine on Fruit-Set of Apple," Acta Horticulturae, Vol. 149, 1984, pp. 189-195.

[5] P. T. Evans and R. L. Malmberg, "Do Polyamines Have Roles in Plant Development?" Annual Review of Plant Physiology and Plant Molecular Biology, Vol. 40, 1989, pp. 235-269. doi:10.1146/annurev.pp.40.060189.001315

[6] M. Faust and S. Y. Wang, "Polyamines in Horticulturally Important Plants," Horticultural Reviews, Vol. 14, 1992, pp. 333-356.

[7] N. Bagni, M. M. Altamura, S. Biondi, M. Mengoli and P. 
Torrigiani, "Polyamines and Morphogenesis in Normal and Transgenic Plant Cultures," In: K. A. RoubelakisAngelakis and K. Tran Thanh Van, Eds, Morphogenesis in Plants, Plenum Press, New York, 1993, pp. 89-111.

[8] A. Bouchereau, C. Duhaze, J. Martin-Tanguy, J. P. Guegan and F. Larher, "Improved Analytical Methods for Determination of Nitrogenous Stress Metabolites Occurring in Limonium Species," Journal of Chromatography $A$, Vol. 836, 1999, pp. 209-221. doi:10.1016/S0021-9673(99)00078-3

[9] R. K. Kakkar and V. P. Sawhney, "Polyamine Research in Plants: A Changing Perspective," Plant Physiology, Vol. 116, No. 3, 2002, pp. 281-292. doi:10.1034/j.1399-3054.2002.1160302.x

[10] G. Costa and N. Bagni, "Effect of Polyamines on Fruit Set of Apple," Horticultural Science, Vol. 18, 1983, pp. 59-61.

[11] B. Kloareg, M. Broquedis and J. M. Joubert, "Fruit Development: Elicitor Effects of Biostimulants," Arboriculture Fruitiere, Vol. 498, 1996, pp. 39-42.

[12] Z. Singh and J. Janes, "Regulation of the Fruit Set and Retention in Mango with Exogenous Application of Polyamines and Their Biosynthesis Inhibitors," Acta Horticulturae, Vol. 509, 2000, pp. 675-680.

[13] N. Alburquerque, J. Egea, L. Burgos, D. MartinezRomero, D. Valero and M. Serrano, "The Influence of Polyamines on Apricot Ovary Development and Fruit Set," Annals of Applied Biology, Vol. 149, No. 1, 2006, pp. 27-33. doi:10.1111/j.1744-7348.2006.00067.x

[14] M. Broquedis, P. Lespy-Labayette and J. Bouard, "Composition en Polyamines des Grappes au Moment de la floraison. Effect de Pulverizations de Crème d'Algue Cryobroyée," Phytoma-La Défense des Végétaux No. 474, 1995.

[15] Anonymous Ag \& Garden Imports, "GOËMAR BM86 Improve Health, Increase Production Naturally," 2008. www.agandgarden.com

[16] M. D. Rethwitch, T. Cox, D. M. Ramos, M. Luna and J. Wellman, "Effect of Goëmar BM86 and Mepiquat Chloride on DPL449BR and DPL 484R Cotton," Arizona Cotton Report (P-145), University of Arizona, 2006, pp. 179-193.

[17] University of Arkansas Cooperative Extension Database Service, "Irrigation Scheduler," 2007.

http://www.aragriculture.org/computer_programs/irrigatio n_scheduling/default.asp

[18] M. A. Smith and P. J. Davies, "Separation and Quantification of Polyamines in Plant Tissue by High Perform- ance Liquid Chromatography of Their Dansyl Derivatives," Plant Physiology, Vol. 78, No. 1, 1985, pp. 89-91. doi:10.1104/pp.78.1.89

[19] O. Lepri, L. Bassie, P. Thu-Hang, P. Christou and T. Cappell, "Endogenous Enzyme Activities and Polyamine Levels in Diverse Rice Cultivars Depend on the Genetic Background and Are Not Affected by the Presence of the Hygromycin Phosphotransferase Selectable Marker," Theoretical Applied Genetics, Vol. 105, No. 4, 2002, pp. 594-603. doi:10.1007/s00122-002-0922-4

[20] S. Sood and P. K. Nagar, "Post-Harvest Alternationsin Polyamines and Ethylene in Two Diverse Rose Species," Acta Physiologiae Plantarum, Vol. 30, No. 2, 2008, pp. 243-248. doi:10.1007/s11738-007-0113-7

[21] R. Biasi, G. Costa and N. Bagni, "Polyamine Metabolism as Related to Fruit Set and Growth," Plant Physiology and Biochemistry, Vol. 29, 1991, pp. 497-506.

[22] C. H. Crisosto, P. B. Lombard, D. G. Richardson, R. Tetley and M. D. Vasilakis, "Effect of Ethylene Inhibitors on Fruit Set, Ovule Longevity and Polyamnies Levels in 'Comice' Pear," Acta Horticulturae, Vol. 179, 1986, pp. 229-236.

[23] C. H. Crisosto, P. B. Lombard, D. Sugar and V. S. Polito, "Putrescine Infuences Ovule Senecence, Fertilization Time, and Fruit Set in 'Comice' Pear," Journal of the American Society for Horticultural Science, Vol. 113, 1988, pp. 708-712.

[24] M. Serrano, M. C. Marinez-Madrid, F. Riquelme and F. Romojaro, "Endogenous Levels of Polyamines and Abscisic Acid in Pepper Fruits during Growth and Ripening," Annals of Applied Biology, Vol. 149, 1995, pp. 2733.

[25] E. Rugini and M. Mencuccini, "Increased Yield in the Olive with Putrescine Treatment," Horticultural Science, Vol. 20, 1985, pp. 102-103.

[26] Z. Singh and L. Singh, "Increased Fruit Set and Retention in Mango with Exogenous Application of Polyamines," Journal of Horticultural Science and Biotechnology, Vol. 70, 1995, pp. 271-277.

[27] F. Antognoni, F. Ghetti, A. Mazzucato, M. Franceschetti and N. Bagni, "Polyamine Pattern during Flower Development in the Parthenocarpic Fruit (par) Mutant of Tomato," Physiologia Plantarum, Vol. 116, No. 4, 2002, pp. 539-547. doi:10.1034/j.1399-3054.2002.1160413.x

[28] E. D. Gonias, D. M. Oosterhuis and A. C. Bibi, "Cotton Radiation Use Efficiency Response to Plant Growth Regulators," Journal of Agricultural Science, Cambridge. Published online 24 October 2011. 